\title{
Intramuscular injection
}

National Diabetes Information Clearinghouse (NDIC)

\section{Definitions}

Syringe

Defined by National Diabetes Information Clearinghouse (NDIC)

Glucagon

Defined by National Diabetes Information Clearinghouse (NDIC)

Subcutaneous injection

Defined by National Diabetes Information Clearinghouse (NDIC)

Hypoglycemia

Defined by National Diabetes Information Clearinghouse (NDIC)

\section{Source}

National Diabetes Information Clearinghouse (U.S.). (2009). The diabetes dictionary. [Bethesda, Md.]: U.S. Dept. of Health and Human Services, National Institutes of Health, National Institute of Diabetes and Digestive and Kidney Diseases, National Diabetes Information Clearinghouse.

Inserting liquid medication into a muscle with a syringe. Glucagon may be given by intramuscular or subcutaneous injection for hypoglycemia. 